\title{
Prevalência e perfil de sensibilidade de amostras de Staphylococcus aureus isoladas de casos clínicos de infecções hospitalares
}

\section{Prevalence and sensibility profiles of Staphylococcus aureus samples isolated from clinical cases of hospital infections}

\section{Prevalencia y perfil de sensibilidad de muestras de Staphylococcus aureus isoladas de casos clínicos de infecciones hospitalares}

\author{
Maria Inez Almeida', J oão Bedendo", Emerson Danguy Cavasin"I', Maria Cristina Bronharo Tognim ${ }^{\prime V}$
}

\begin{abstract}
RESUMO
Este estudo investigou a prevalência e o perfil de sensibilidade de amostras de Staphylococcus aureus isoladas de casos clínicos de infecções hospitalares, em um hospital de ensino, Londrina - Paraná, no período de 2001 a 2004. Foi também comparado os resultados dos testes de susceptibilidade a oxacilina e vancomicina de 74 cepas, obtidos pelo sistema automatizado MicroScan ${ }^{\circledR} \quad$ (Dade Bering, Sacramento, Califórnia, USA, utilizando Painéis MicroScan ${ }^{\circledR}$ PC 12 (Gram Positivo), com os resultados da técnica de diluição em ágar com diferentes concentrações destes antimicrobianos. As informações foram procedentes do banco de dados das infecções hospitalares da Comissão de Controle de Infecção Hospitalar $(\mathrm{CClH})$. As amostras de $\mathrm{S}$. aureus apresentaram amplo espectro de resistência frente as drogas testadas. A taxa média de prevalência de infecções hospitalares por S. aureus foi de $16,3 \%$ e a taxa média de prevalência de amostras oxacilina resistentes foi de $70,75 \%$. Não se detectou amostras resistentes a vancomicina pelos 2 métodos. O método de diluição em ágar confirmou a resistência a oxacilina em 65 das $74 \quad(83,75 \%)$ e as amostras avaliadas pelo sistema MicroScan ${ }^{\circledR}$ não apresentaram diferenças estatisticamente significantes. Para o antimicrobiano vancomicina, houve concordância em 100\% entre os dois métodos.
\end{abstract}

Palavras chave: Staphylococcus aureus; Oxacilina; Vancomicina; Infecção Hospitalar.

\section{ABSTRACT}

This study investigated the prevalence and the susceptibility profile of Staphylococcus aureus samples isolated from clinical infections in a teaching hospital, Paraná - Londrina, cases between 2001 and 2004 . The sensitivity test results for 74 strains to oxacillin and vancomycim, obtained by MicroScan ${ }^{\circledR}$ automated system (Dada Bering, Sacramento, California, USA, employing MicroScan ${ }^{\circledR}$ PC 12gram positive Panels) were compared with the results obtained from the dilution agar method using different concentrations of antimicrobials. The data was obtained from the Hospital Infection Committee Control Data bank. The Staphylococcus aureus samples showed a large spectrum of resistance to the antimicrobials tested. The medium rate of prevalence of the S. aureus hospital infections was $16,3 \%$ and the medium rate of prevalence of the hospital infection, by oxacillin resistant $\mathrm{S}$. aureus strains was $70,75 \%$. It was not detected samples resistant to vancomycin using both methods. Among this 74 samples identified as oxacillin-resistant by MicroScan ${ }^{\circledR}$ system, 65 $(83,75 \%)$ had their resistance confirmed by Dilution Agar Method. The difference between the results was not statistically significant. To the vancomycin, there was $100 \%$ of concordance in both methods.

Key words: Staphylococcus aureus; Oxacilin; Vancomicin; Hospital Infection. 


\section{RESUMEN}

En este estudio se investigó la prevalencia y el perfil de sensibilidad de muestras de Staphylococcus aureus aisladas de casos clínicos de infecciones hospitalarias, en un hospital de enseñanza, Londrina - Paraná, en el período de 2001 a 2004. Fue también comparado los resultados de las pruebas de susceptibilidad a la oxacilina y vancomicina de 74 cepas, obtenidos por el sistema automatizado MicroScan ${ }^{\circledR}$ (Dade Bering, Sacramento, California, EE.UU., utilizando Paneles MicroScan ${ }^{\circledR}$ PC 12 (Gram Positivo), con los resultados de la técnica de dilución en agar con diferentes concentraciones de estos antimicrobianos. Las informaciones fueron procedentes del banco de datos de las infecciones hospitalarias de la Comisión de Control de Infección Hospitalaria $(\mathrm{CClH})$. Las

\section{NTRODUÇÃO}

O Staphylococcus aureus tem ocupado lugar de destaque na etiologia das infecções hospitalares e sua alta versatilidade em adquirir resistência aos antimicrobianos tornouse uma preocupação universal ${ }^{(1)}$

No Brasil estudos têm demonstrado prevalência de infecções hospitalares por S. aureus variando entre $17 \%$ a $26 \quad \%$ e aproximadamente $70 \%$ a $100 \%$ são causadas por amostras multirresistentes ${ }^{(1-4)}$.

Sader $^{(5)}$ refere que diante da disseminação de bactérias multirresistentes é necessária a adoção de programas de vigilância que envolve, entre outras medidas, a avaliação do perfil de sensibilidade dos isolados empregando se metodologias apropriadas e recomendadas por órgãos de referência.

o perfil de sensibilidade aos antimicrobianos pode ser determinado pelo método de difusão em ágar, diluição em placa ou tubo e também através de equipamentos, de diferentes graus de automação, que fornecem valores quantitativos de pontos de muestras de S. aureus presentaron un amplio espectro de resistencia frente a las drogas probadas. La tasa promedio de prevalencia de infecciones hospitalarias por $\mathrm{S}$. aureus fue de $16,3 \%$ y la tasa promedio de prevalencia de muestras oxacilina resistentes fue de $70,75 \%$. No se detectó muestras resistentes a la vancomicina por los 2 métodos. El método de dilución en agar confirmó la resistencia a la oxacilina en 65 de las $74(83,75 \%)$. Muestras evaluadas por el sistema MicroScan ${ }^{\circledR}$ siendo que esta diferencia entre osa 2 métodos no fue estadísticamente significante. Para el antimicrobiano vancomicina, hubo concordancia de $100 \%$ entre los dos métodos.

Palabras clave: Staphylococcus aureus; Oxacilina; Vancomicina; Infecciones hospitalarias.

corte que permitem aproximar os valores de concentração inibitória mínima - (CIM). Tal valor é determinado pela concentração mínima de um medicamento capaz de inibir o crescimento bacteriano, sob condições próprias de incubação e de tempo ${ }^{(5-7)}$.

O emprego do teste para determinação da CIM apresenta recomendação para a análise de resistência a oxacilina em amostras de S. aureus. Nos testes de sensibilidade a drogas antimicrobianas, a resistência a oxacilina é um marcador de resistência que se estende a todos os betalactâmicos ${ }^{(5,7)}$.

No que se refere a vancomicina foram isoladas amostras de $\mathrm{S}$. aureus resistentes no Brasil $^{(4,8)}$

Cerca de $80 \%$ das infecções estafilocócicas vem sendo tratadas com vancomicina $^{(8)}$ e há referência de que o uso em larga escala e por tempo prolongado pode induzir o aparecimento de estirpes resistentes $^{(4,9-10)}$

Considerando o exposto, o presente estudo teve como objetivo determinar a 
prevalência e o perfil de sensibilidade de amostras de $\mathrm{S}$. aureus isoladas de casos clínicos de infecção hospitalar bem como comparar os resultados dos testes de sensibilidade à oxacilina e vancomicina obtidos com o emprego de duas metodologias.

\section{MÉTODOS}

Este estudo foi desenvolvido em um hospital de ensino público do Estado do Paraná, considerado centro de referência para o Sistema Único de Saúde. Conta com 333 leitos e faz aproximadamente 1.150 internações por mês.

As informações referentes a ocorrência de infecções hospitalares, ocorridas entre 2001 e 2004, foram obtidas junto ao banco de dados da Comissão de Controle de Infecção Hospitalar $(\mathrm{CClH})$ e os resultados dos testes de sensibilidade das cepas de Staphylococcus aureus foram procedentes do relatório do sistema automatizado MicroScan $\left.{ }^{\circledR}\right)$, Dade Bering, Sacramento, Califórnia, USA, utilizando Painéis MicroScan ${ }^{\circledR}$ PC 12 (Gram Positivo).

Setenta e quatro cepas de Staphylococcus aureus resistentes a oxacilina e sensíveis a vancomicina foram reavaliadas quanto à sensibilidade a oxacilina e vancomicina pela técnica de diluição em ágar, em placas contendo diferentes concentrações destes antimicrobianos, conforme recomendações do National Committe for Clinical Laboratory Standards ${ }^{(11)}$.

Os resultados obtidos com as duas técnicas foram comparados empregando se teste estatístico para proporção(12)

Os dados deste estudo foram cadastrados em planilha do programa Excel, tabulados e analisados para se determinar o perfil de sensibilidade das amostras de Staphylococcus aureus aos antimicrobianos.

O presente estudo foi analisado e aprovado pelo Comitê de Ética em Pesquisa do Hospital Universitário Regional do Norte do Paraná, parecer CEP 002/05, por estar em conformidade com a Resolução 196/96 Conselho Nacional de Saúde (CNS) (BRASIL, 1996).

\section{RESULTADOS}

A média da prevalência das infecções hospitalares por S. aureus, no período de 2001 a 2004 , foi de $16,3 \%$ e a taxa de infecção hospitalar por Staphylococcus aureus oxacilina resistente - (ORSA) foi de 11\%. A distribuição média da resistência das amostras de $\mathrm{S}$. aureus isoladas de infecções hospitalares no período de 2001 a 2004 da instituição em estudo foi: penicilina, 50/52 (98\%); eritromicina, $42 / 54(79,25 \%)$; ciprofloxacin, $23 / 38(63,25 \%)$; clindamicina, $31 / 40(76,5 \%)$; cloranfenicol, 16/22 (71,75\%); trimetoprimsulfametoxazol, $32 / 44(71,25 \%)$; tetraciclina, 11/18 (56\%); rifampicina, 4/36 (11,25\%).

Para a oxacilina e vancomicina foram avaliadas 236 amostras de S. aureus sendo que a prevalência média de resistência a oxacilina foi de $70,75 \%$. A taxa de resistência anual foi de $74 \%$ em 2001; $75 \%$ em 2002; $66 \%$ em 2003 e $68 \%$ em 2004.

Não se observou resistência a vancomicina durante o período. Entre as setenta e quatro amostras de $\mathrm{S}$. aureus identificadas como resistentes a oxacilina através do método MicroScan ${ }^{\circledR}$, os resultados mostraram que em 83,78 \% (65/74) houve confirmação desta resistência pela técnica de diluição em placa. Aplicando o teste para a 
proporção, não se rejeita $\mathrm{H} 0$, ou seja, a proporção de microrganismos encontrada é $100 \%$, ( $p$-valor $=0,14773$ ).

Para a vancomicina, em $100 \%$ das amostras de S. aureus houve confirmação da sensibilidade pela técnica de diluição em placa.
O perfil de sensibilidade aos antimicrobianos de amostras de Staphylococcus aureus isoladas de casos clínicos de infecção hospitalar, de um hospital de ensino, no período de 2001 a 2004, é apresentado na Figura 1.

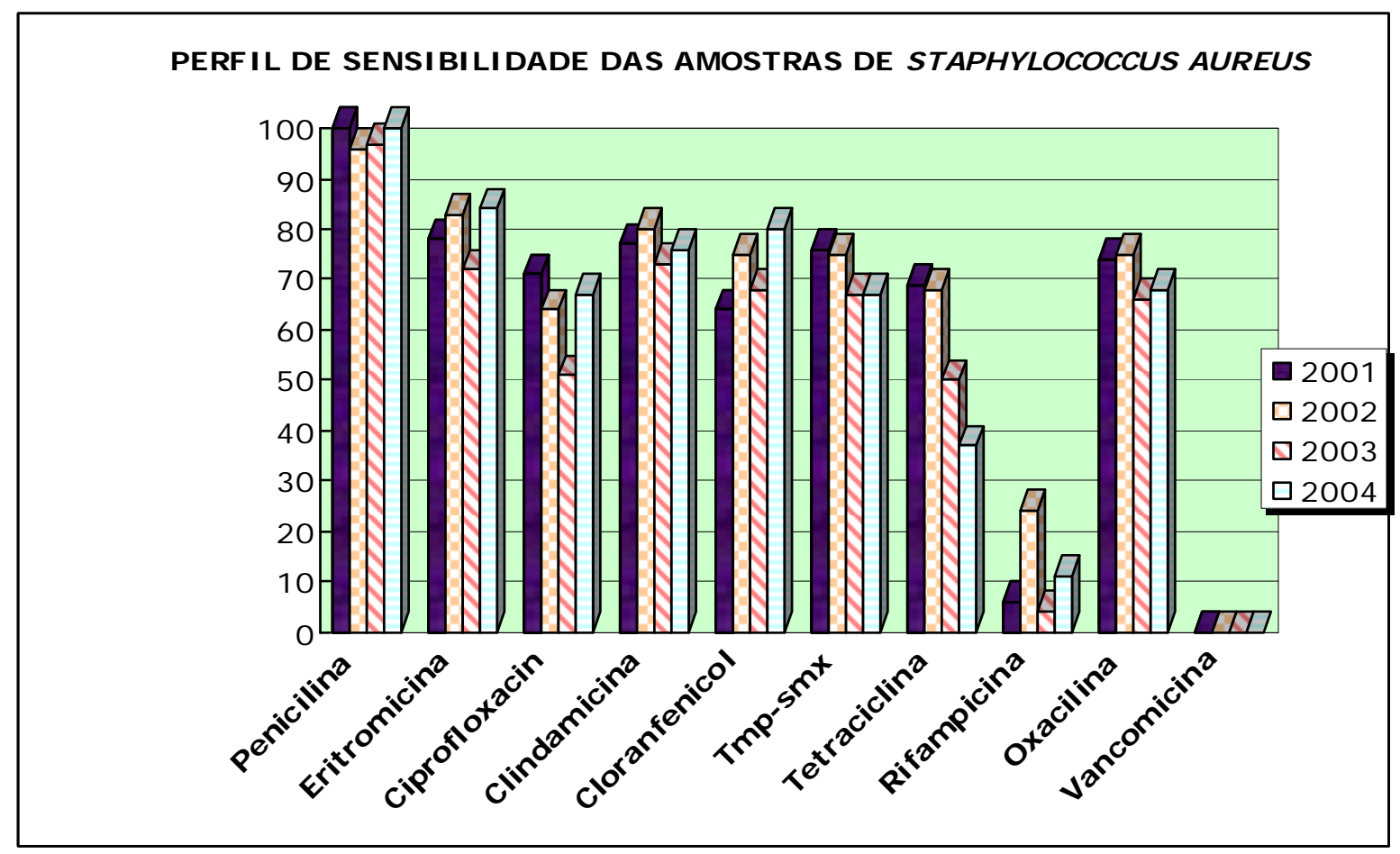

Figura 1: Perfil de sensibilidade aos antimicrobianos de amostras de Staphylococcus aureus isoladas de casos clínicos de infecção hospitalar, de um hospital de ensino, em Londrina - Paraná, no período de 2001 a 2004.

\section{SCUSSÃO}

Determinar a prevalência de ocorrência de infecção hospitalar é uma estratégia epidemiológica importante para a proposição de medidas de prevenção e controle e também um dos critérios mais utilizados para a escolha da terapêutica ${ }^{(2,3,6,13-14)}$.

Neste estudo o S. aureus, apresentou uma taxa média de prevalência de $16,3 \%$, se destacando como agente etiológico de casos clínicos de infecções hospitalares o que corrobora estudos realizados em outras instituições no Brasil que demonstraram valores variando entre $17 \%$ e $26 \%^{(1-4)}$

Organismos internacionais, entretanto ainda não estabeleceram níveis aceitáveis para as taxas de infecções hospitalares e cada instituição deve estabelecer suas metas em função de suas características.

Condições tecnológicas, capacitação técnica de pessoal, níveis de atendimento, tipo de paciente albergado e especialidades médicas são, entre outros, fatores importantes que influenciam na aquisição de infecção(1-2) 
Os S. aureus possuem um conjunto de mecanismos de virulência e grande versatilidade de estratégias patogênicas, o que influi no desenvolvimento da resistência a antibióticos e eleva a vulnerabilidade à infecção ${ }^{(4,7,9,15-16)}$.

Neste estudo a taxa média de prevalência de ORSA, entre as infecções estafilocócicas hospitalares, foi de $70,75 \%$.

Estes resultados estão de acordo com aqueles de estudos isolados realizados no Brasil, que demonstraram taxas de prevalência de ORSA, entre as infecções hospitalares estafilocócicas, variando de $40 \%$ a $80 \%{ }^{(3-4,15-}$ 17)

Há também um estudo multicêntrico, realizado em 11 hospitais brasileiros, no qual a taxa de ORSA, entre as infecções estafilocócicas hospitalares, foi de $43,7 \%{ }^{(3)}$.

A América do Sul apresenta um dos índices mais altos de resistência bacteriana em infecções hospitalares ${ }^{(5)}$. A identificação de cepas ORSA em instituições hospitalares é uma ferramenta epidemiológica importante, pois estas estirpes atuam como marcador para outros grupos de antimicrobianos, como, aminoglicosídeos, macrolídeos, e cefalosporinas $^{(10,15,17)}$. A taxa média de resistência a ciprofloxacin foi de $63,25 \%$, clindamicina, $76,5 \%$, tetraciclina, 56\%, e para trimetoprim-sulfametoxazol de $71,25 \%$.

Em estudo realizado em hospitais brasileiros, entre 1995 e 1997, demonstraram a existência de um clone endêmico de ORSA resistente à ciprofloxacin, eritromicina, lincomicina, trimetroprim-sulfametaxasol e a tetraciclina. Neste estudo não se procedeu a análise molecular das amostras ORSA para se identificar a existência de correlação clonal entre os isolados ${ }^{(18)}$.

A avaliação da resistência aos aminoglicosídeos é importante, uma vez que essa classe de antibióticos pode ser associada a betalactâmicos e glicopeptídeos para tratamento de infecções graves. Durante o período avaliado a resistência média a gentamicina foi $66,75 \%$.

Amicacina foi avaliada somente em 2003 e a resistência encontrada foi de $67 \%$. Estas taxas são menores que aquelas de outro estudo (14) realizado com amostras de 12 hospitais de São Paulo, onde se constatou taxas de resistência de $91 \%, 96 \%$ e $82 \%$ respectivamente para amicacina, gentamicina e sulfonamidas. Salienta-se que os resultados acima foram procedentes de estudos realizados com amostras resistentes e sensíveis a oxacilina entre os anos de 1990 e 1992.

A ciprofloxacin, pertencente ao grupo das quinolonas, apresentou taxa média de resistência de $63,25 \%$, resultados estes semelhantes em estudo que detectou resistência de $62 \%^{(14)}$. Staphylococcus spp pode desenvolver resistência durante a terapia prolongada com quinolonas e tornar-se resistentes em três a quatro dias após o início do tratamento ${ }^{(11)}$.

A resistência a oxacilina resulta em resistência cruzada a todos os antibióticos betalactâmicos, tais como penicilinas, cefalosporinas e carbapenêmicos. As cefalosporinas de primeira geração apresentam melhor atividade contra os gram-positivos quando comparadas com as de terceira geração $^{(5,11,15,17)}$.

As cepas testadas frente às cefalosporinas, neste estudo, apresentaram um 
perfil de resistência superior a $50 \%$, com exceção do ano de 2003. Este resultado não era esperado uma vez que perfil de sensibilidade da penicilina se manteve estável neste período. O uso de cefalosporinas eleva possibilidade do aparecimento de Enterococcus resistentes a vancomicina, e esta condição é problemática já que esta resistência, sendo mediada por plasmídios, pode ser transferida a outras bactérias incluindo Staphylococcus aureus $^{(8-10,15,17)}$

Nos hospitais, o tratamento prolongado com antibióticos de amplo espectro, como a vancomicina, tornam difícil o controle destas infecções ${ }^{(8,18)}$.

O aumento da freqüência de infecções hospitalares causadas por ORSA é acompanhado pelo aumento da resistência a muitos outros antimicrobianos com atividade antiestafilocócica, como os aminoglicosídeos, cloranfenicol, lincosamídeos, macrolídeos, quinolonas e tetraciclina, resultando em poucas alternativas terapêuticas para o tratamento ${ }^{(18)}$.

As técnicas de diluição em ágar e o método automatizado MicroScan ${ }^{\circledR}$, para o antimicrobiano vancomicina, desenvolvida neste estudo, demonstrou ausência de resistência a vancomicina para todas as cepas de S. aureus testadas. Estas técnicas são amplamente abordadas na literatura ${ }^{(3,10-11,17,19)}$ e S. aureus resistente a vancomicina podem ser confiavelmente detectados.

Microrganismos que apresentarem valores de $\mathrm{CIM}$ elevados para vancomicina devem ser enviados a um laboratório de referência para confirmação de resultado (11), pois tanto a tolerância quanto a resistência a vancomicina são considerados fenômenos instáveis e induzidos que surgem durante o tratamento com a droga ${ }^{(18)}$.

O surgimento da tolerância é considerado o início do desenvolvimento da resistência a

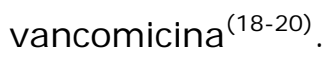

Para determinação de resistência a oxacilina, os resultados apontaram que em $87,83 \%$ (65/74) houve concordância entre as duas metodologias. Através da técnica de diluição em Agar a resistência a oxacilina foi detectada em 65 das 74 amostras avaliadas. Aplicando se o teste para proporções foi obtido um $\mathrm{p}$-valor $=0,14773$ demonstrando não haver diferença estatisticamente significante na confiabilidade dos métodos empregados.

\section{CONCLUSÃO}

As amostras de Staphylococcus aureus apresentaram um amplo espectro de resistência frente aos antimicrobianos usualmente empregados na prática clínica. Não se observou resistência a vancomicina entre as amostras avaliadas. Não houve diferença estatisticamente significante nos resultados obtidos com a aplicação da técnica de diluição em ágar e o método automatizado (MicroScan ${ }^{\circledR}$ ) na detecção de amostras Staphylococcus aureus resistentes a oxacilina.

Houve concordância nos resultados das técnicas de diluição em ágar e o método automatizado (MicroScan ${ }^{\circledR}$ ) na avaliação da susceptibilidade a vancomicina.

\section{REFERÊNCI AS}

1. Ribeiro Filho N. Resistência bacteriana aos antibióticos. In Fernandes AT, Fernandes MOV, Ribeiro Filho N. Infecção hospitalar e suas interfaces na área da saúde. São Paulo (SP): Atheneu; 2000.

2. Almeida EA. Bactérias multirresistentes. In: Couto RC, Pedroso TMG. Guia prático de 
controle de infecção hospitalar: epidemiologia, controle e terapëutica. $2 \underline{a}$ ed. Rio de Janeiro (RJ): Medsi; 2004.

3. Sader HS, Mendes RE, Gales AC, Jones RN, Pfaller MA, Zoccoli $C$, et al. Perfil de sensibilidade a antimicrobianos de bactérias isoladas do trato respiratório baixo de pacientes com pneumonia internados em hospitais brasileiros - Resultados do Programa SENTRY, 1997 e 1998. Jornal de Pneumologia 2001; 27(2): 59-67.

4. Tavares W. Bactérias gram-positivas problemas: Resistência do estafilococo, do enterococo e do penumococco aos antimicrobianos. Revista da Sociedade Brasileira de Medicina Tropical 2000;33(3): 281-301.

5. Sader HS. Bactérias multirresistentes: microbiologia, epidemiologia e controle. Prática Hospitalar. Entrevista [serial online] 2003 [cited 2005 maio 30]; 5(30). Available from: URL:

http: ://www. praticahospitalar.com.br/pratica\% 2030/pagina/materia\% 2003-30.html

6. Brasil. Ministério da Saúde. Agência Nacional de Vigilância Sanitária. Curso básico de controle de infecção hospitalar - Caderno D: Microbiologia aplicada ao controle de infecção hospitalar [online] 2000 [cited 2005 maio 10]. Available from: URL: http://200.144.0.25/pdf/Cl HCadernoD.pdf

7. Leme IL, Pignatari ACC. Estafilococias. In: Ferreira AW, Ávila SLM. Diagnóstico laboratorial, avaliação de métodos de diagnóstico das principais doenças infecciosas e parasitárias e auto-imunes. Correlação clínicolaboratorial. Rio de Janeiro (RJ): Guanabara Koogan; 1996.

8. Bernardes RC, Jorge $A O C$, Leão MVP. Sensibilidade à oxacilina, vancomicina e teicoplanina de Staphylococcus coagulase positivos isolados de pacientes hospitalizados em São José dos Campos. Revista de Biociências 2004; 10(1/2): 73-8.

9. Murray PR, Rosenthal KS, Kobayashi GS, Pfaller MA. Agentes antibacterianos. In: Murray PR, Rosenthal KS, Kobayashi GS, Pfaller MA. Microbiologia médica. 4a a ed. Rio de Janeiro (RJ) Guanabara Koogan; 2004. p.17280.

10. Oliveira GA, Okada SS, Guenta RS, Mamizuka EM. Avaliação da tolerância a vancomicina em 395 cepas hospitalares de Staphylococcus aureus resistentes à oxacilina. Brazilian Journal of Infectious Diseases 2001; 37(4): 239-46.
11. National Committe For Clinical Laboratory Standards. Normatizações para antibiograma. Wayne; 2004.

12. Magalhães MN, Lima ACP. Noções de probabilidade e estatística. São Paulo (SP):USP; 2002.

13. Brasil. Ministério da Saúde. Agência Nacional de Vigilância Sanitária. Manual de microbiologia clínica para o controle de infecção em serviços de saúde. Brasília; 2004.

14. Farias WVL, Sader HS, Leme IL, Pignatari AC. Padrão de sensibilidade de 117 amostras clínicas de Staphylococcus aureus isoladas em 12 hospitais. Revista da Associação Médica Brasileira 1997; 43(3): 199-204.

15. Beretta AIRZ, Trabasso P, Stucchi RB, Moretti L. Use of molecular epidemiology to monitor the nosocomial dissemination of methicillin-resistant Staphilococcus aureus in a University Hospital from 1991 to 2001. Brazilian Journal of Medical and Biological Research 2004; 37: 1345-51.

16. Castro, M. Bactérias multirresistentes. In: Couto RC, Pedroso TMG, Nogueira J M. Infecção hospitalar e outras complicações nãoinfecciosas de doença: epidemiologia, controle e tratamento. 3a ed. Rio de Janeiro $(R J)$ : Medsi; 2003.

17. PEREIRA, M. S. V. . Staphylococcus aureus: o microvilão da resistência a antibióticos. A UNIÃO, J oão Pessoa - Paraíba, 19 jan. 2002.

18. Oliveira GA, Faria JB, Levy CE, Mamizuka EM. Characterization of the brazilian endemic clone of methicillin-resistant Staphylococcus aureus (MRSA) from hospitals throughout. Brazilian Journal of Infectious Diseases 2001; 5(4): 163-70.

19. Murray PR, Rosenthal KS, Kobayashi GS, Pfaller MA. Staphylococcus e microrganismos correlatos In: Murray PR, Rosenthal KS, Kobayashi GS, Pfaller MA. Microbiologia médica. 4a ed. Rio de Janeiro (RJ): Guanabara Koogan, 2004. p. 188-201.

20. Sader HS. Abordagem laboratorial para bactérias gram-positivas multirresistentes. In: Curso de Teste de Sensibilidade e Controle de Qualidade, 1, 2000; São Paulo. São Paulo: UNIFESP, Laboratório Especial de Microbiologia Clínica; 2000.

Artigo recebido em 13.12.06

Aprovado para publicação em 28.08.07 